\title{
Parallelism of Association Rules Mining and Its Application in Insurance Operations ${ }^{\star}$
}

\author{
Jinlan Tian, Lin Zhu, Suqin Zhang, and Gang Huang \\ Department of Computer Science and Technology \\ Tsinghua University., Beijing, 100084, PR China \\ tjlan@mail.tsinghua.edu.cn
}

\begin{abstract}
Association rules mining is a basic method in data mining. This paper first introduces the basic concepts of association rules mining and Apriori algorithm. It also provides a parallel association rules model scheme for improving the mining efficiency when treating large numbers of data sets as well as the analyse of the scheme effect. In conclusion we discuss how to apply association rules mining to insurance data sets, find out the knowledge hidden behind the data sets, and provide powerful decision-making support for people.
\end{abstract}

Keywords: data mining; association rules mining; parallel algorithm; insurance

\section{Introduction}

Data Mining is an advanced process to find and extract confident, novel, effective and comprehensible patterns which are hidden behind a mass of data sets [1] [2]. Along with the prevalence of database, many large-scale companies collect the data as many as billions of or ever more. The huge data sets should be well understood for providing information for company directors. The ability of dealing with large data sets is crucial for data mining tools.

Association rules mining is an important pattern of knowledge patterns of data mining. The concept of association rules mining, which is simple and practical, is provided by Agrawal£Imielinski and Swami 1. The patterns of association rules mining belong to descriptive patterns, and the algorithms to discover rules belong to unsupervised learning. In this paper, we first introduce the definition and attributes of association rules mining, and Apriori, the algorithm which has close relationship to it. Then we present a design of parallel scheme of association rules mining. At last, we discuss how to utilize MineSet, a data mining tool of SGI, into insurance data sets to dig out association rules.

* This research is supported by a joint research grant from National Science Foundation of China (project No.60131160743) and Hong Kong Research Grant Council. 


\section{The Definition and Attributes of Association Rules Mining}

Just pay attention to some transactions that relate to many items: item $X$ appears at transaction 1, item $Y$ appears at transaction 2, and item $X$ and $Y$ appear at transaction 3 simultaneously. Therefore, are there any rules of item $X$ and $Y$ appear at transactions? In the area of data mining, association rules act as such knowledge patterns which describe the rules of items appearing at the same transaction simultaneously. More exactly, association rules describe how the appearance of item $X$ affects the appearance of item $Y$ through quantification. Some basic concepts of association rules are rendered below 4 .

Let $R=\left\{I_{1}, I_{2}, \cdots, I_{m}\right\}$ be a set of items. Let $W$, the task-relevant data, be a set of database transaction where each transaction $\mathrm{T}$ is a set of items such that $T \subseteq R$. Let $A$ be a set of items. A transaction $T$ is said to contain $A$ if and only if $A \subseteq T$. An association rule is an implication of the form $A \Rightarrow B$, where $A \subset I, B \subset I$, and $A \cap B=\emptyset$. Here are the four basic attributes of associate rules 3 .

Confidence. The rule $A \Rightarrow B$ has confidence $c$ in the transaction set $W$ if $c$ is the percentage of transactions in $W$ containing $A$ that also contain $B$. Confidence is the scale of veracity of association rules.

Support. The rule $A \Rightarrow B$ holds in the transaction set $W$ with support $s$, where $s$ is the percentage of transactions in $W$ that contain $A \cup B$ (i.e., both $A$ and $B$ ). Support is the scale of weightiness of association rules. The bigger the support, the more important the rule is. 5

Expected confidence. The rule $A \Rightarrow B$ has expected confidence $e$ in the transaction set $W$ if $e$ is the percentage of transactions in $W$ that contain $B$.

Lift. Lift is the ratio of confidence and expected confidence. Lift describes how the appearance of $A$ affects the appearance of $B$. Generally speaking, available association rules should have the lift that is bigger than 1 .

\section{Parallelism of Association Rules Mining Algorithm}

\subsection{Algorithm of Association Rules Mining}

Rules that satisfy both a minimum support threshold (min_sup) and a minimum confidence threshold (min_conf) are called "strong" 6]. "How are association rules mined from large databases?" Association rule mining is a two-stop process:

- Find all frequent itemsets: By definition, each of these itemsets will occur at least as frequently as a pre-determined minimum support count.

- Generate strong association rules from the frequent itemsets: By definition, these rules must satisfy minimum support and minimum confidence.

Additional interestingness measures can be applied, if desired. The second step is the easier of the two. The overall performance of mining association rules is determined by the first step. 
Aprior 7] 8] is a basic algorithm for mining frequent itemsets for Boolean association rules. Aprior employs an iterative approach known as a level-wise search, where $k$-itemsets are used to explore $(k+1)$-itemsets. First, the set of frequent 1-itemsets is found. This set is denoted $L_{1} . L_{1}$ is used to find $L_{2}$, the set of frequent 2-itemsets, which is used to find $L_{3}$, and so on, until no more frequent $k$-itemsets can be found. The finding of each $L_{k}$ requires one full scan of the database.The pseudocode for the Apriori algorithm is shown below.

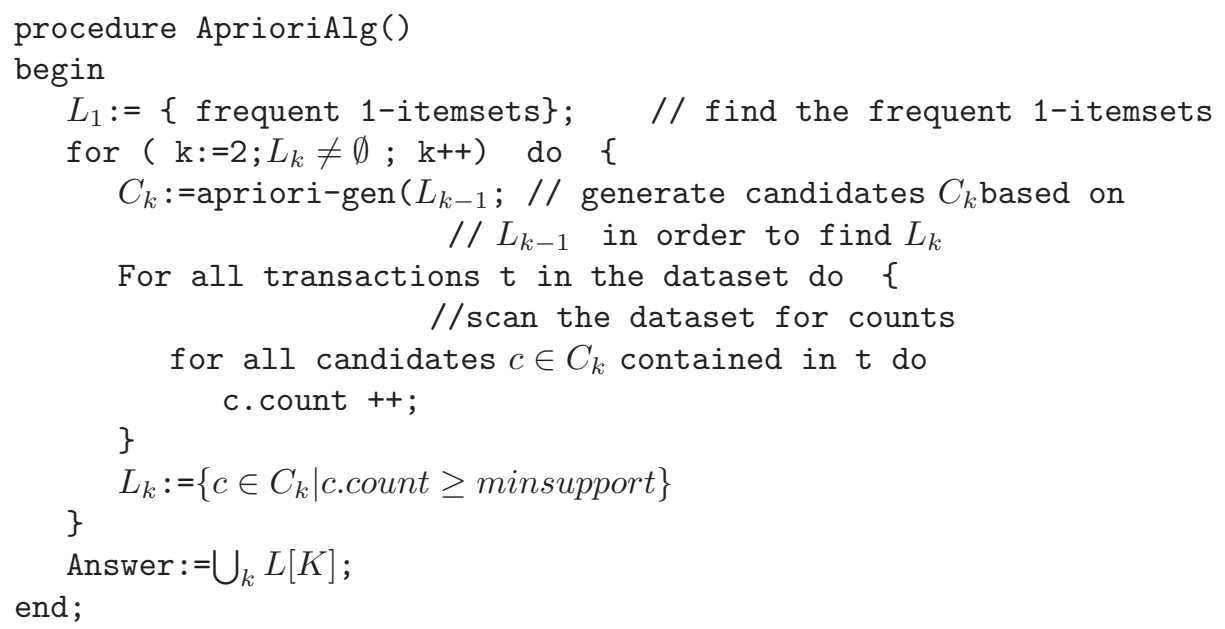

The database is scanned repetitious times in Apriori algorithm. The first scan of Apriori finds the frequent 1-itemsets. The every following scan, for example, the $k$ th scan, firstly use $L_{k-1}$ to generate candidates $C_{k}$, and then scan the whole database to find grequent itemsets in $C_{k}$ and put them into $L_{k}$.

\subsection{Parallel Scheme Design}

Data mining always treats very large members of data, often millions of records in some data sets. It will cost insufferably long time for data mining tools to deal with these records. So the ability of dealing with huge numbers of data sets is crucial to data mining tools. They need parallel technologies.

Most job of the Apriori algorithm is about the scanning and statistics of data. However, the statistics is independent transversely (among association rules) and longitudinally (among records). Therefore, the data should be distributed to multi-processors. Two schemes here.

1) Longitudinal partition

Every processor runs an integrated algorithm under such partition. But each processor treats with different columns of data records. For more detail, count combinative modes among columns of records, and then every processor treats with one kind of combinative mode to build association rules of the data treated with. For example, there are three columns $\left(F_{1}, F_{2}, F_{3}\right)$ in records. There are three kinds of combinative modes according to every two combination. Assign 
them into three separate processors, and then we will get the related association rules.

However, the efficiency of this partition method is far from satisfying. Because:

- There are many repetitious statistics because some different records involve the same columns.

- The bottleneck of the algorithm we discussed is the scan of database. But the longitudinal partition does not solve this problem effectively.

2) Transverse partition

Divide the data into $\mathrm{n}$ parts in such partition methods, and assign the $n$ parts into $n$ processors. Then collect the statistical results at last $[9]$.

It will spend most of time in Apriori algorithm to scan databases and count the frequency that the items appear. So it is the key issue to make this module into parallel.

There are two characters in this kind of parallel:

- Regard the record as unit, so the data are independent of each other. Different records will not affect each other.

- Different records share the same handle process.

Therefore we could use SIMD model[10 to construct out parallel algorithm. First, divide the data into $n$ parts, assign them into $n$ processor to parallel, and synthesize the results at last. The processors are not required to be synchronous.

Figure 1 shows the flow chart of transverse partition method:

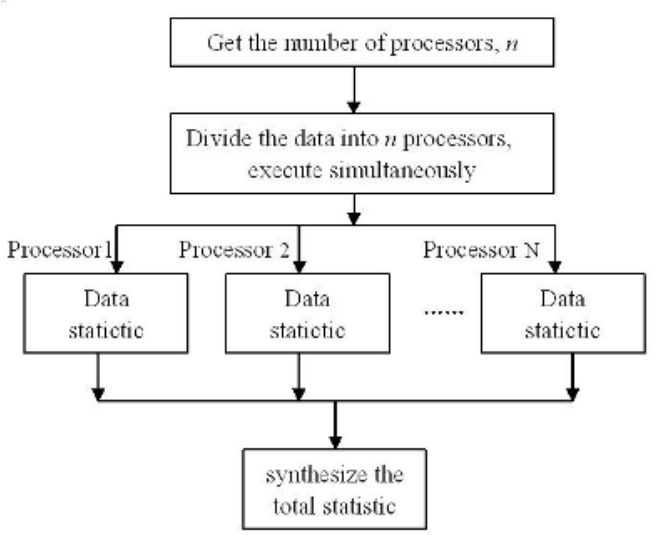

Fig. 1. Flow chart of transverse partition method

In conclusion, we do not need to consider the data-correlation problem and the synchronization of processors. This scheme is so effective that it can reduce the execution time to the ratio of almost $1 / n$ towards the primary algorithm. 


\section{Application in Insurance Operations}

Association rules can be used in many fields, such as merchandise retail, finance, insurance and so on. There are many data mining tools implementing the association rules mining method at present. Now we will discuss how to utilize MineSet 11, a data mining tool provided by SGI Company, to operate insurance data with association rules.

1) Data Preparation

Here are the records in the data data resource.

\begin{tabular}{|c|c|c|c|c|c|c|c|}
\hline $\begin{array}{l}\text { Individua } \\
\text { Insurance } \\
\text { ID }\end{array}$ & Age & $\begin{array}{l}\text { Total } \\
\text { Salary } \\
\text { per Year }\end{array}$ & Company ID & $\begin{array}{l}\text { Company } \\
\text { Name }\end{array}$ & $\begin{array}{l}\text { Com- } \\
\text { pany } \\
\text { Type }\end{array}$ & $\begin{array}{l}\text { Com- } \\
\text { pany } \\
\text { Area } \\
\text { Code }\end{array}$ & $\begin{array}{l}\text { Com- } \\
\text { pen- } \\
\text { sation } \\
\text { Times }\end{array}$ \\
\hline $\begin{array}{l}35020438 \\
08264031\end{array}$ & 60 & 7,051 & 0000000664 & $\begin{array}{l}\text { Oil company } \\
\text { of city A }\end{array}$ & 3 & 3 & 0 \\
\hline $\begin{array}{l}35020421 \\
04054011\end{array}$ & 77 & 7,382 & 0000000664 & $\begin{array}{l}\text { Oil company } \\
\text { of city A }\end{array}$ & 3 & 3 & 1 \\
\hline $\begin{array}{l}13242745 \\
12206811\end{array}$ & 53 & 17,617 & 0000000663 & $\begin{array}{l}\text { The third } \\
\text { Middle } \\
\text { school of city } \\
\text { A }\end{array}$ & 2 & 1 & 0 \\
\hline \begin{tabular}{|l|}
31011072 \\
03033631
\end{tabular} & 26 & 15,485 & 0000000662 & $\begin{array}{l}\text { Government } \\
\text { of city A }\end{array}$ & 2 & 1 & 0 \\
\hline
\end{tabular}

Each record includes the basic information of a policy holder and the times he has claimed for compensation. We want to find out the characters of people who have claimed form compensation and those whose have not. The data should be prepared before mining. As we just concern the Compensation Times and its related information, the redundant information in the dataset, such as individual insurance ID, company ID and company name, should be removed.

Take notice of age and total salary per year, they are continuous. But when using association rules, the association rules generated algorithms cannot deal with continuous data and should be discretized. Divide the attribute age into five groups (..40], (40..50], (50...60], (60...70] and (70...); total salary per year into three groups £...6,000], $(6,000 \ldots 10,000]$ and $(10,000 \ldots]$.

As for the attribute of compensation times, we only concern whether a policy holder claimed or not, and ignore the concrete number of compensation times. Thus attribute compensation times are converted to If Compensating, 1 represents compensated and 0 represents not. Here are the data after convertion.

\begin{tabular}{|l|l|l|l|l|}
\hline Age & $\begin{array}{l}\text { Total Salary per } \\
\text { Year }\end{array}$ & $\begin{array}{l}\text { Type of } \\
\text { Company }\end{array}$ & $\begin{array}{l}\text { Company Area } \\
\text { Code }\end{array}$ & $\begin{array}{l}\text { Compensa- } \\
\text { ting }\end{array}$ \\
\hline$(50 \ldots 60)$ & $(6,000 \ldots 10,000]$ & 3 & 3 & 0 \\
\hline$(70 \ldots)$ & $(6,000 \ldots 10,000]$ & 3 & 3 & 1 \\
\hline$(50 \ldots 60)$ & $(10,000 \ldots]$ & 2 & 1 & 0 \\
\hline$(\ldots 40)$ & $(10,000 \ldots]$ & 2 & 1 & 0 \\
\hline$\ldots \ldots$
\end{tabular}


2) Mine Association Rules

We need to specify the minimum support and minimum confidence. Take the minimum support as $1 \%$. As minimum support rises, the rules we can find reduce, so the time used in mining will reduce. But if minimum support is too high, we may miss some rules which should be found. We take the minimum credibility as $50 \%$, before using MineSet.

3) Visualized Display and Comprehend the Rules

When MineSet find out Association rules, it will use Scatter Visualize 11 to display the mining result. Figure 2 illustrates the result.

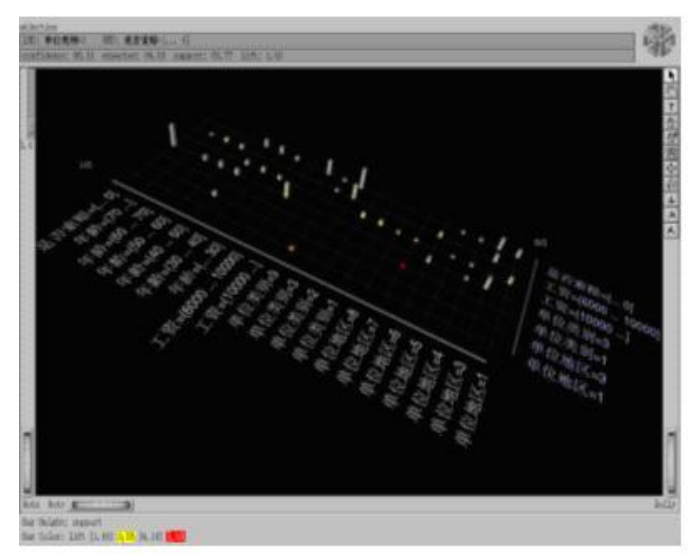

Fig. 2. Association rules mining result

It is a three-dimensional picture. The first is LHS (left-hand side) to represents the items set A. The second is RHS (right-hand side) to represent the items set $\mathrm{B}$. Every oblong in the figure represents an association rule $A \Rightarrow B$, as $\mathrm{A}$ is the value projected on LHS, B is the value projected on RHS.

The third dimension is the height of an oblong which represents the confidence of the rule. The color of every oblong shows the lift of the rule. (each color stands for an area of lift, you can find the corresponding relations at the bottom left corner of the figure). When the mouse is on an oblong, the information of corresponding association rule will be displayed at top left of the screen. For example, the information included in the oblong in the figure above is:
LHS
Company Type=3 RHS
If Compensating $=0$

confidence: 85.18 expected: 84.00 support: 60.77 lift: 1.03

So the association rule which the oblong in the picture stands for is: Company Type $=3 \Rightarrow$ If Compensating $=0$. The value of the four parameters of this rule is: Support $=60.77 \%$, Confidence $=85.18 \%$, Expected Confidence $=84.00 \%$, Lift $=$ 1.03.

We can see, $84.00 \%$ of all policy holders have not claimed for compensation, $60.77 \%$ have done and their company type is 3 . Among the policy holders whose company type is $3,85.13 \%$ have not claimed for compensation. "Lift $=1.03$ " 
tells us that "Company Type= 3 " does not have a considerable affection on whether the policy holders has claimed or not. It is because that without this term the compensation rate of policy holders does not has an obvious change.

Some of the association rules gained are not useful to insurance business, such as the association rules between total salary per year and company type, and ignored.

In the association rules we have just mentioned, LHS and RHS include only one item. They are one-to-one single rules. If more items for LHS and RHS are permitted, multi-corresponding association rules 12 can be obtained. They are shown with Record Visualize:

\begin{tabular}{|c|c|c|c|c|c|}
\hline Support & Confidence & Expected & Lift & LHS & RHS \\
\hline 1.9997 & 84.77 & 84 & 1.0091 & $\begin{array}{l}\text { Company } \\
\text { Type }=2 \\
\text { Age }=\left(\begin{array}{lll}40 & \ldots & \text { 50 }\end{array}\right]\end{array}$ & $\begin{array}{l}\text { If Compensa- } \\
\text { ting }=0\end{array}$ \\
\hline 3.4213 & 92.8 & 84 & 1.1047 & $\begin{array}{ll}\text { Company } & \text { Area } \\
\text { Code }=5 & \end{array}$ & $\begin{array}{l}\text { If Compensa- } \\
\text { ting }=0\end{array}$ \\
\hline 1.6091 & 86.55 & 84 & 1.0304 & $\begin{array}{lr}\text { Company } & \text { Area } \\
\text { Code }=6 & \text { and } \\
\text { Age }=\left(\begin{array}{lll}30 & \ldots & 40\end{array}\right]\end{array}$ & $\begin{array}{l}\text { If Compensa- } \\
\text { ting }=0\end{array}$ \\
\hline 15.1695 & 93.1 & 84 & 1.1083 & $\begin{array}{l}\text { Company } \\
\text { Type }=3 \\
\text { Age }=\left(\begin{array}{lll}40 & \ldots & \text { and }\end{array}\right]\end{array}$ & $\begin{array}{l}\text { If Compensa- } \\
\text { ting }=0\end{array}$ \\
\hline 2.2653 & 87.88 & 84 & 1.0461 & $\begin{array}{l}\text { Company area } \\
\text { Code }=4 \text { and } \\
\text { Total Salary per } \\
\text { Year }=(6000 \quad \ldots \\
10000]\end{array}$ & $\begin{array}{l}\text { If Compensa- } \\
\text { ting }=0\end{array}$ \\
\hline
\end{tabular}

A row represents an association rule. The columns show LHS, RHS and other four parameters. We can see that among the people whose company type is 3 and age is between 40 and 50 years old, 93.1\% have not claimed for compensation, much higher than expected confidence. However, among the people whose company type is 2 and age is between 40 and 50 years old, $84.77 \%$ have not claimed for compensation. If these results are based on some external reason, (For example, the companies with the company type 3 do not bring too much pressure to their employees, so the employees are not so tired to catch ill easily.) insurance company then may pay more attention on those customers who meet such conditions above for reducing the investment venture and increase operation earnings. When those rules are applied in practice, they should be adjusted with the time goes by. Then we can gain the most appropriate and best results that they are the closest to the original requirements.

\section{Conclusion}

In this paper we present the parallel scheme design of association rules mining and its application on insurance data. Parallel data mining algorithms are effec- 
tive methods to solve the performance problem when treating large numbers of data sets. Association rules mining can be utilized into many areas other than insurance, such as credit card company, stock exchange and bank. Markets could use association rules to decide what to buy and how to put goods. In addition, association rules mining also has great affects in the application on communication industry, it can be used to analyze the factors of customer loss, adjust preferential action in time and reduce the loss of important customers. In conclusion, association rules mining can be applied at various areas widely, discover the knowledge hidden behind the data, and provide powerful decision-making support for people.

\section{References}

1. Peatetsky-Shapiro, G., Fayyad, U., and Smyth, P., From Data Mining to Knowledge Discovery: An Overview, Fayyad, U.M., Piatetsky-Shapiro, G., Smyth, P., and Uthurusamy, R., (eds), Advances in Knowledge Discovery and Data Mining, AAAI/MIT Press, pp.1-35,1996

2. Introduction to data mining and knowledge discovery, Third Edition, by Two Crows Corporation

3. K.Decker and S.Focardi, Technology Overview: A Report on Data Mining, Technical Report CSCR TR-95-02, Swiss Scientific Computing Center, 1995

4. Heikki Mannnila, Hannu Toivonen and A. Inkeri. Verkamo, Efficient algorithms for discovering association rules, AAAI Workshop on Knowledge Discovery in Databases, pages 181-192, July 1994

5. Tony Xiaohua Hu, Knowledge Discovery in Databases: An Attribute-Oriented Rough Set Approach, Ph.D. thesis, Regina university, 1995

6. Gao Wen, KDD Knowledge Discovery in Databases, Computer World, vol. 37, 1998

7. Rakesh Agrawal, Manish Mehta, John Shafer and Ramakrishnan Srikant, The Quest Data Mining System, AAAI/MIT Press, pp.244-249,1996

8. R.Feldman, A.Amir, Y.Auman, A.Zilberstien and H.Hirsh, Incremental Algorithms for Association Generation, AAAI/MIT Press,pp.227-241,1995

9. Z.Zhang Y.Lu and B.Zhang, An Effective Partitioning-Combining Algorithm for Mining Quantitative Association Rules, AAAI/MIT Press,pp.241-252,1995

10. Chen Guoliang, Design and Analysis of parallel algorithms, Higher Education publishing company, China, 2002

11. SGI Company, MineSet2.0 Tutorial

12. David W.Cheung, Vincent T.Ng and Benjamin W.Tam, Maintenance of Discovered Knowledge: A Case in Multi-level Association Rules, AAAI/MIT Press, pp.307309,1996 